\title{
Effect of Propylthiouracil on Nycthemeral and Sex Related Variation of Plasma TSH in Rats
}

\author{
Nobuhiko TONOOKA and Setsuo KOBAYASHI
}

\author{
First Department of Internal Medicine, School of Medicine \\ Gunma University, Maebashi, Gunma 371, Japan
}

\begin{abstract}
Synopsis
Studies of the effect on feedback mechanisms in nycthemeral fluctuation of plasma TSH and of its sex-related variation were carried out on normally fed (Purina) and propylthiouracil (PTU) treated rats. Plasma TSH concentration of purina fed rat was significantly higher in males than in females $(M=96 \pm 14, F=49 \pm 3 \mu \mathrm{u} / \mathrm{ml}, \mathbf{P}<$ 0.01). Plasma T4 concentration also showed a high tendency in males compared to females $(\mathrm{M}=7.4 \pm 0.5, \mathrm{~F}=5.8 \pm 1.0 \mu \mathrm{g} / \mathrm{d} l, 0.05<\mathrm{P}<0.1)$ but the statistical difference was not significant.

Plasma TSH demonstrated a typical periodicity characterized by a zenith at $1200 \mathrm{hr}$ and a nadir at $1800 \mathrm{hr}$ as in the previous reports. Plasma TSH concentrations rose apparently after the diet was switched to the one containing $0.15 \%$ of PTU. On the other hand, plasma T4 concentrations decreased to the very low levels following PTU administration. Concerning to the nycthemeral fluctuation and its sex related variation following PTU administration, nycthemeral fluctuation in male rats disappeared rapidly, whereas it was preserved in female rats. These facts showed that it kept more persistent fluctuation in female rats than in male rats under the high plasma TSH levels. Furthermore, female rats showed higher concentration of plasma TSH after PTU treatment compared to male rats.

These results suggest that the nycthemeral fluctuation of plasma TSH was abolished or masked by the feedback mechanism of hypothalamo-pituitary-thyroid axis and there was a sex-related difference.
\end{abstract}

The presence of circadian rhythmic variation in the secretion of pituitary hormones has been demonstrated in man and in animals (Hellman et al., 1970; Krieger et al., 1971; Lemarchand-Beraud et al., 1969; Quabbe et al., 1971). Available reports have demonstrated a nycthemeral fluctuation of plasma TSH in man and in animals in the euthyroid state (Hershman et al., 1971; Juquet et al., 1971; Webster et al., 1972). Studies on the time of zenith and nadir in the circadian variation of plasma TSH, however, revealed variable data (Fukuda et

Received March 29, 1979. et al., 1975; Leppaluoto et al., 1974; Nicoloff et al., 1970). Moreover, it has been noted that nycthemeral fluctuation of plasma TSH is abolished in severe hypothyroidism (Saberi et al., 1974; Webster et al., 1972). Although these observations have been confirmed in man and in rats, the existence of nycthemeral fluctuation of plasma TSH has been observed in mild hypothyroidisms in man (Week et al., 1976). In addition, nycthemeral fluctuation of plasma TSH in hypothyroidisms has never been estimated in relation to the sex difference. The present study reports further observations on the circadian variation of plasma TSH of hy- 
pothyroidisms acutely induced by propylthiouracil (PTU) treatment in rats in order to clarify the effect of feedback mechanisms induced by low plasma T4 levels following PTU administration on the circadian variation of plasma TSH and to see its sex related difference in acutely induced hypothyroidism.

\section{Materials and Methods}

Total seventy-nine age-mached male and femals Sprauge-Dawley rats weighing maximal $250 \mathrm{~g}$ were used in the present study. The control animals were maintained on purina laboratory chow containing $3 \mathrm{mg}{ }^{127} \mathrm{I} / \mathrm{Kg}$ and tap water ad libitum. PTU treated animals were fed on $0.15 \%$ propylthiouracil (PTU) contained experimental food. Three to four animals of the same sex were housed in the same cages at $24 \pm 1^{\circ} \mathrm{C}$ in an artificially illuminated room. Lights were on from 0600 to $1800 \mathrm{hr}$ and off from 1800 to $0600 \mathrm{hr}$.

\section{First Experiment}

Seven male rats of each group were sacrified every $6 \mathrm{hr}$ from $0600 \mathrm{hr}$ an one day to $0600 \mathrm{hr}$ an the following day. These animals were accustomed to the enviromental condition and handled for two weeks prior to the experiment. The animals were immediately decapitated in another room after removal from the cages. The trunk blood was collected in heparinized plastic tubes.

\section{Second Experiment}

Twelve rats, 6 males and 6 females were used. Rats of both sexes were bleeded between 1800 and $1830 \mathrm{hr}(\mathrm{PM})$ and between 1130 and $1200 \mathrm{hr}$ (AM) on one day to compare the plasma TSH and T4 levels following PTU administration (0, 3, 14 day) to minimize the nycthemeral variation of plasma TSH. The blood was obtained from the subclavian vein by the transcutaneal bleeding method within two minutes under light ether anesthesia.

\section{Third Experiment}

Experiment was carried out in the same way as in the second one for 14 days under PTU administration.

All samples were stored at $-20^{\circ} \mathrm{C}$ until analysed. Plasma corticosterone was measured by fluoresence method (Guillemin et al., 1059). Plasma TSH and T4 were determined by radioimmunoassay (Tonooka et al., 1978). Rat TSH kit was obtained from the NIAMDD Rat pituitary hormone program. All of the samples from each experiment were measured in the same assay run. Coefficints of variations of intra and inter assays were less than $12 \%$ for all assays. Statistical analyses were calculated by multifactorial analysis of variance, product-moment correlation and Student's $t$, or paired t- test.

\section{Results}

Experiment 1. Comparison of nycthemeral rhythm of plasma TSH and plama corticosterone levels in male rats.

It appeared that the highest value of plasma TSH was noted when the plasma corticosterone showed its lowest value as if the inverse relation were present between plasma TSH and plasma corticosterone (Fig. 1). No correlation was, however, observed between plasma TSH and plasma corticosterone $(r=-0.27, p>0.1)$.

Experiment 2. Nycthemeral fluctuation of plasma TSH and plasma T4 following acute PTU administration.

Plasma TSH concentrations on purina fed rats were significantly higher in males than in females $(M=96 \pm 14, F=49 \pm 3$ $\mu \mathrm{u} / \mathrm{m} l, \mathrm{p}<0.01)$.

Following PTU treatment, male rats did not show any significant difference of nycthemeral fluctuation of plasma TSH, but female rats still exhibited nycthemeral rhythm for 14 days after PTU administration (Fig. 2). Plasma T4 concentration showed a high tendency in males compared to females but the statistical difference was not significant $(\mathrm{M}=7.4 \pm 0.5, \mathrm{~F}=5.8 \pm 1.0$ $\mu \mathrm{g} / \mathrm{d} l, 0.05<\mathrm{p}<0.1)$. Plasma T4 levels in both sexes were reduced to the very low levels after PTU administration 3 days of (Fig. 3), but plasma T4 concentration of nycthemeral variation showed paradoxical results compared to purina rats.

Experiment 3. Nycthemeral and sex related variation of plasma TSH after acute PTU treatment.

Fig. 4 depicts the changes of nycthe- 


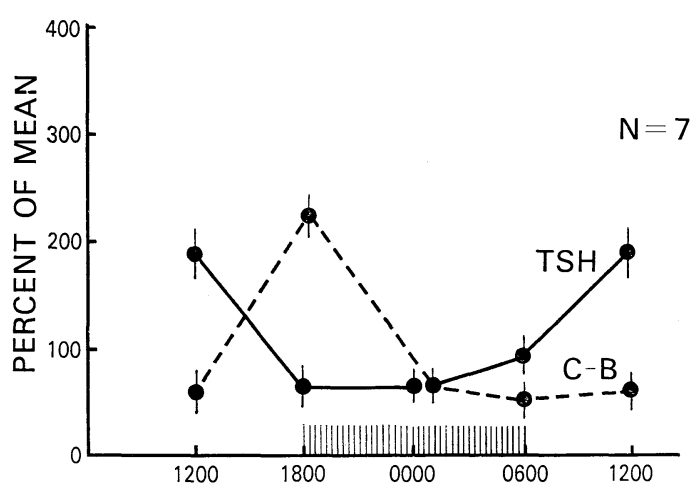

Fig. 1. Nycthemeral variation of plasma TSH and corticosterone (B) through a $24 \mathrm{hr}$ period in purina rats: The shaded horizontal bar indicates the period of darkness. Plasma TSH and corticosterone are represented by solid lines and dotted lines, respectively. All values are indicated by percent of mean of plasma TSH and corticosterone. Mean values of plasma TSH and corticosterone are $99.7 \mu \mathrm{u} / \mathrm{m} l$ and $11.2 \mu \mathrm{g} / 100 \mathrm{~m} l$ respectively. Each point represents the mean and each vertical bar the standard error.
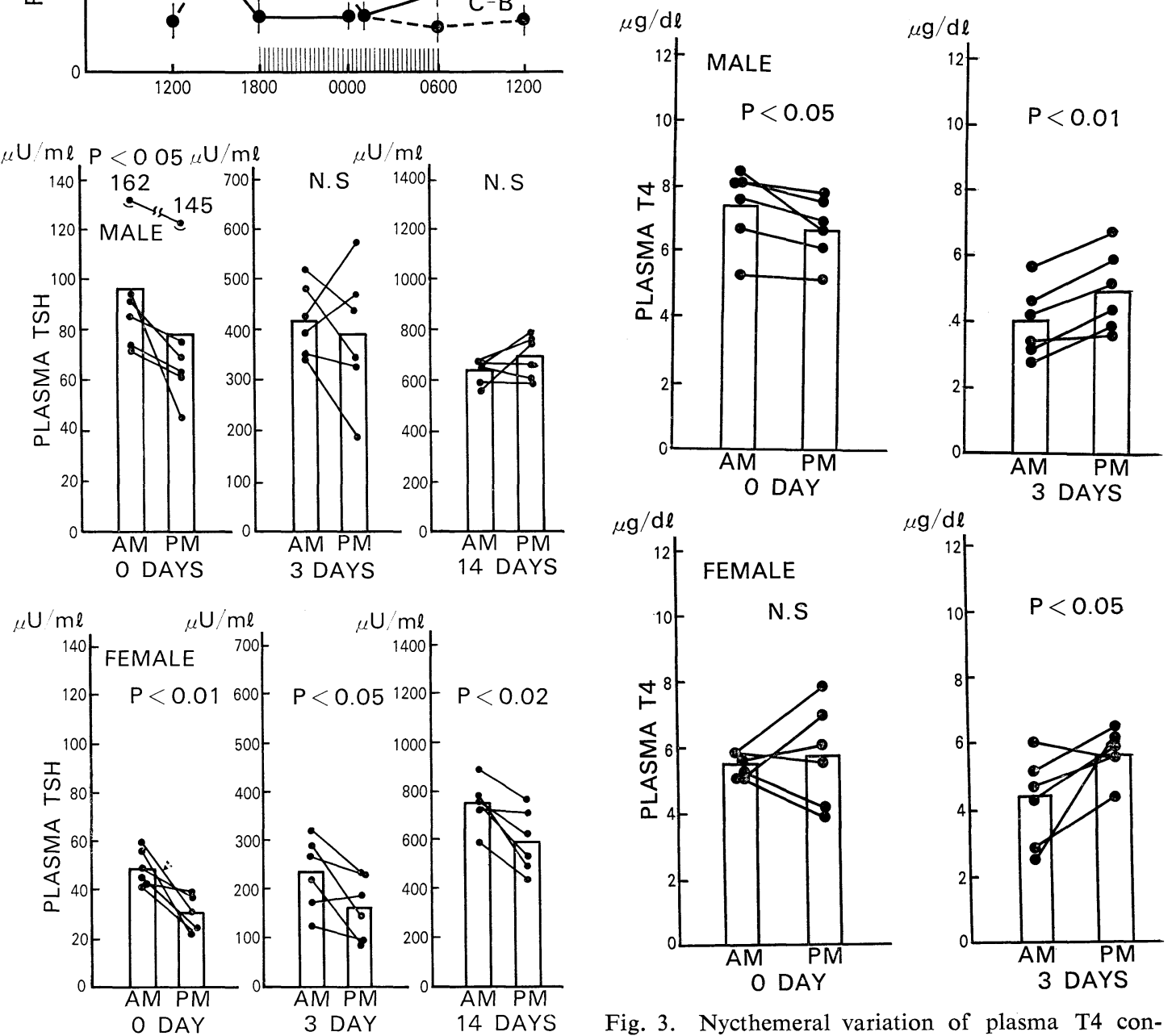

Fig. 2. Nycthemeral variation of plasma TSH concentration on the PTU treated rats: The height of each bar represents the mean of plasma TSH concentration. Statistical comparison was performed by paired t-test. Upper panel shows the change of plasma TSH concentration in male rats and lower that panel shows that in female rats following PTU administration (0, 3, 14 days).

Fig. 3. Nycthemeral variation of plasma T4 concentration in PTU treated rats: The height of each bar represents the mean of plasma T4 concentration. Statistical comparison was performed by paired t-test. Upper panel shows the change of plasma T4 concentration in male rats and lower panel shows it in female rats following PTU administration (0, 3 days). All plasma T4 levels of 14-day PTU treated rats are shown ni nondetectable levels. 


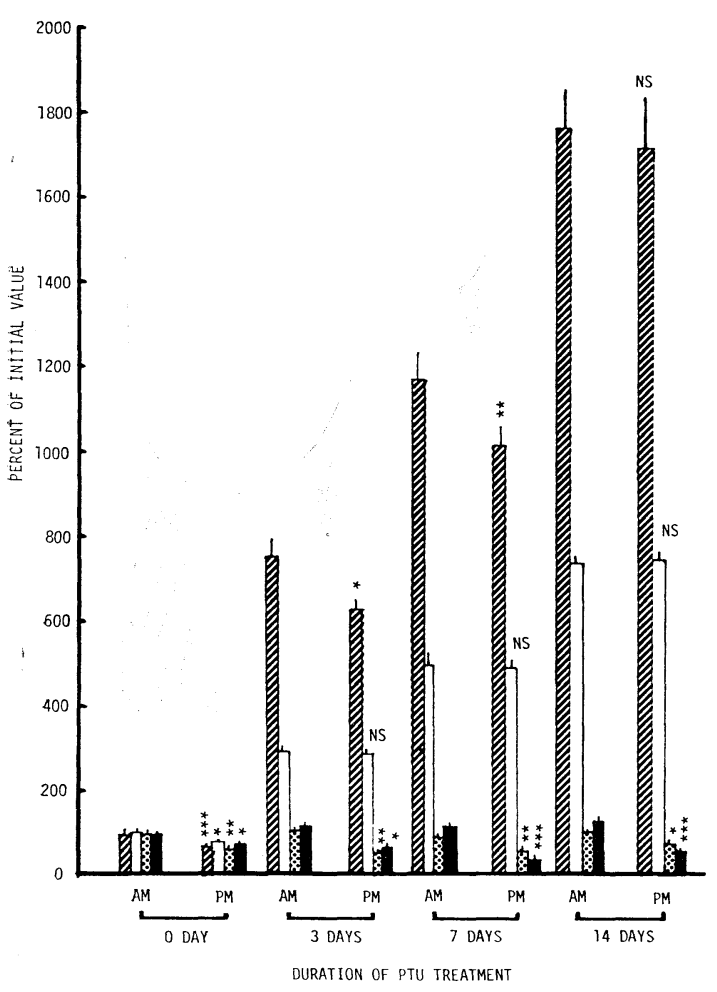

Fig. 4. Change of nycthemeral and sex variation of plasma TSH following PTU administration: Comparison of nycthemeral and sex variation of plasma TSH in male (open bars) and in female (hatched bars) rats following PTU treatment. Plasma TSH of male and female rats in the control are shown by shaded bars and dotted bars respectively. The number of animals in each group is ten. Each value represents the percent of initial value. Results are shown as mean and SE. Statistical differences (vs. AM) are shown by asterisks. $* \mathbf{P}<0.05$, ** $\mathbf{P}<0.02$, *** $\mathbf{P}<0.01$. meral fluctuation of plasma TSH and sexrelated variation following PTU administration. Apparently female rats showed higher levels of plasma TSH compared to male rats on PTU treatment $(\mathrm{p}<0.01-0.02)$ and female rats showed more prominent fluctuation of nycthemeral rhythm than male rats. The values of plasma TSH were represented in Table 1. In contrast to the Exp. 2, the nycthemeral fluctuation of plasma TSH after PTU administration for 14 days disappeared in both sexes.

\section{Discussion}

In the present study, we have demonstrated that the circadian variation of plasma TSH is present and have a sex related variation in the acute stage of hypothyroidism produced by PTU treatment. The rhythm and sex variation will be absent under the stage of more advanced feedback induced by chronic PTU administration because nycthemeral fluctuation of plasma TSH was observed to be abolished under severe hypothyroid situation (Saberi et al., 1974; Webster et al., 1972). The mechanism underlying the diurnal plasma TSH rhythm and sex-related variation are largely unknown so far. Available reports postulated some possibilities about the cause of the circadian variation of plasma TSH.

The neural mechanism which has already been postulated for other hormonal rhythms

Table 1. Circadian and sex related variation of plasma TSH levels following PTU administration: All values are mean \pm S.E. Statistic differences (vs. $1200 \mathrm{~h}$ ) are shown by asterisks. Statistical analysis is calculated by paired t-test. $* \mathbf{P}<0.05$, ** $\mathbf{P}<0.02$, *** $\mathbf{P}<0.01$.

\begin{tabular}{|c|c|c|c|c|c|c|c|c|c|c|}
\hline \multirow{2}{*}{ Group } & \multirow{2}{*}{ Sex } & \multirow{2}{*}{$\mathrm{N}$} & \multicolumn{2}{|c|}{0 Day } & \multicolumn{2}{|c|}{3 Days } & \multicolumn{2}{|c|}{7 Days } & \multicolumn{2}{|c|}{14 Days } \\
\hline & & & $\mathrm{AM}$ & PM & $\mathrm{AM}$ & PM & $\mathrm{AM}$ & PM & AM & PM \\
\hline Purina & $\mathbf{M}$ & 10 & $106 \pm 15$ & $55 \pm 9 *$ & $141 \pm 28$ & $68 \pm 15^{*}$ & $105 \pm 20$ & $67 \pm 15^{* *}$ & $133 \pm 22$ & $69 \pm 14^{* * *}$ \\
\hline PTU & $\mathbf{M}$ & 10 & $103 \pm 12$ & $62 \pm 10 *$ & $292 \pm 17$ & $273 \pm 19$ & $513 \pm 35$ & $486 \pm 36$ & $769 \pm 52$ & $771 \pm 58$ \\
\hline Purina & $\mathrm{F}$ & 10 & $47 \pm 6$ & $31 \pm 2^{* *}$ & $47 \pm 6$ & $30 \pm 3^{* *}$ & $50 \pm 6$ & $31 \pm 2^{* * *}$ & $56 \pm 6$ & $39 \pm 4^{* *}$ \\
\hline PTU & $\mathrm{F}$ & 9 & $55 \pm 7$ & $42 \pm 6^{* * *}$ & $422 \pm 33$ & $352 \pm 35^{*}$ & $645 \pm 53$ & $566 \pm 40^{* *}$ & $976 \pm 72$ & $951 \pm 98$ \\
\hline
\end{tabular}


was considered to be the origin of observed circadian variations. The sleep-wake cycle is suggested to be another factor in defining the period (Parker et al., 1976). A presumed cause of the circadian variation of plasma TSH is the fluctuation in thyrotropin releasing hormone (TRH) secretion (Nicoloff et al., 1970; Singer et al., 1973). Since thyroxine was suggested to exert a positive feedback on TRH synthesis, the severely hypothyroid state might lead to a depressed secretion of TRH (Reichlin et al., 1973). In the severe hypothyroid state, the TSH secretion is high due to the lack negative feedback inhibition from peripheral thyroid hormones at the pituitary level because very low thyroxine level showed a damped pituitary-thyroid feedback system (Seif and Kling1er., 1975). The depression of TRH secretion may induce a loss of rhythmicity or result in fluctuations too small to alter measurably the high TSH level (Weeke et al., 1976). This could explain the relation between peripheral thyroid hormone concentrations as showing low plasma T4 levels following PTU administration and the matter of abolished circadian variation of plasma TSH observed in the present study. Another possibility indicates that the circadian rhythm of TSH is the result of a negative feedback from free thyroxine and free triiodothyronine (Weeke, 1973). Conflicting results, however, have been proposed for the diurnal rhythm of the thyroxine (Costre et al., 1971; Lemarchand -Beraud et al., 1969).

In our study, plasma concentration of T4 decreased to very low level (less than 0.3 $\mu \mathrm{g} / \mathrm{d} l) \quad 3$ days after PTU administration while nycthemeral fluctuation of plasma TSH was preserved in female rats. On the other hand, it has been observed that the fluctuation of plasma T4 was accompanied by the changes of plasma volume, total protein, hematocrit, PBI, TBG and prealbumin in man (Costre et al., 1971). Some investigators have postulated that the change of T4 concentration was only a reflection of the cyclic movement of fluids into and out of the vascular compartments and did not represent cyclic secretory patterns (Costre et al., 1971). Hence, there might be present a problem about the replacement of $\mathrm{T} 4$ to cause the fluctuation of plasma TSH. However, there is little reason to believe that fluctuation in TSH secretion might be triggered by changes in free T4 levels, since the biological active form of thyroxine shows no fluctuation (Costre et al., 1971).

Another possibility is the change of TSH which may be regulated by the corticosterone level in serum since an inverse relation between corticosterone and TSH has been proposed by some investigators (Nicoloff et al., 1970). Although our present study could not demonstrate any correlation between plasma TSH and plasma corticostrone, the effect of plasma corticosterone on the sex difference of plasma TSH, can not entirely be excluded because of the higher concentration of corticosterone generally observed in female rats (Fukuda et al., 1975). At present no physiological explanation can be proposed for this circadian characteristics and sex difference on the conservation of circadian rhythm against TSH feedback mechanism produced by PTU administration.

The conclusion, we have found that the feedback mechanism in the hypothalamopituitary-thyroidal axis played a powerful role in the abolishment of nycthemeral fluctuation of plasma TSH in PTU treated animals. Of further interest, a sex difference was noted that the female rats failed to lose the diurnal variation in plasma TSH even after PTU treatment. The marked discrepancy betweeen male and female in sustaining the nycthemeral fluctuation in acute hypothyroidism is hard to explain completely. Further studies will be required for these questions. 


\section{Acknowledgements}

We wish to thank Dr. Monte A. Greer (Division of Endocrinology, University of Oregon Medical School, Portland, Oregon, U.S.A.) for his kind advice. We are also grateful to Miss. Michiko Aoki for her secretarial help.

\section{References}

Costre, P., M. Buhler, L. J. De Groot and S. Refetoff (1971). Metabolism 20, 782.

Fukuda, H., M. A. Greer, L. Roberts, C. F. Allen, V. Critchlow and M. Wilson (1975). Endocrinology 97, 1424.

Gullemin, R. G., G. W. Clayton, H. S. Lipscomb and J. D. Smith (1959). J. Lab. Clin. Med. 58, 830.

Hellman, L., F. Nakada, J. Curti, E. D. Weitzman, J. Krean, H. Roffwarz, S. Felman, D. K. Fukushima and T. F. Gallagher (1970). J. Clin. Endocrinol. 30, 411.

Hershman, J. M. and J. A. Pittman (1971). Ann. Intern. Med. 74, 481.

Juquet, P., P. Franchimont, J. P. Rimaldi, J. M. Saintry, J, L. Codaccioni and J. Vague (1971). Ann. Endocrinol. 32, 495.
Krieger, D. T., W. Allen, F. Rizzo and H. P. Krieger (1971). J. Clin. Endocrinol. 32, 266.

Lemarchand-Beraud, T. and A. Vannotti (1969). Acta Endocrinol. 60, 315.

Leppaluoto, J., T. Ranta and J. Toumisto (1974). Acta Physiol. Scand. 90, 699.

Nicoloff, J. T., D. A. Fisher and M. D. Appleman Jr. (1970). J. Clin. Invest. 49, 1922.

Parker, D. C., Pekary, A. E. and J. M. Hershman (1976). J. Clin. Endocrinol. 43, 318.

Quabbe, H. J., H. Helge and S. Kubichi (1971). Acta Endocrinol. 67, 767.

Reichlin, S. and M. Mitnick, W. F. Ganong and L. Martini. Frontiers in Neuroendocrinology, edited by Oxford University Press, New York, p. 61 (1973).

Saberi, M. and R. D. Utiger (1974). J. Clin. Endrocrinol. 39, 923.

Singer, P. A. and J. T. Nicoloff (1973). J. Clin. Invest. 52, 1099.

Seif, F. J. and W. Klingler (1975). Experientia 15, 863.

Tonooka, N. and M. A. Greer (1978). Endocrinology 102,852 .

Webster, B. R., A. R. Guansing and J. C. Paice (1972). J. Clin. Endocrinol. 34, 899.

Weeke, J. and P. Laurberg (1976). ibid. 43, 32.

Weeke, J. (1973). Scand. J. Clin. Lab. Invest. 31, 337. 